\title{
Inducible Clindamycin Resistant Strains of Staphylococcus aureus - Associated Skin and Soft Tissue Infection
}

\author{
Harish Ghogare ${ }^{1}$ and Sunil Hatkar ${ }^{2 *}$ \\ ${ }^{1}$ Department of Microbiology, MGM Medical College, Aurangabad, India \\ ${ }^{2}$ Department of Microbiology, SMBT Medical College, Nashik, India \\ *Corresponding author
}

\section{Keywords}

Staphylococcus aureus, SSTIs, AST

Article Info

Accepted:

10 September 2018

Available Online:

10 October 2018

\section{A B S T R A C T}

Staphylococcus aureus causes skin and soft tissue infections (SSTIs), if not treated with proper antimicrobials can leads to serious form of infection. Multi-drug resistant strains left us very few therapeutic alternatives, in such cases clindamycin can be a good option with true sensitivity. The clinical samples exhibiting skin and soft tissue infection received in the department of microbiology further subjected to isolation of Staphylococcus aureus. Isolated strains further subjected to D-test to detect inducible clindamycin resistant strains as per standard guidelines. Antimicrobial susceptibility testing performed for all the isolates as per CLSI guidelines. A total of 176 Staphylococcus aureus, 82 were isolated from skin and soft tissue infection. Out of 82 strains, 23(28\%) were inducible clindamycin resistant strains of Staphylococcus aureus, 49(59.8\%) were constitutive resistant, and $10(12.2 \%)$ were MS phenotype. All the isolates were sensitive to vancomycin, followed by doxycyclin 62(75.6\%), Amikacin 60(73.2\%) and 57(69.5\%) were sensitive to linezolid. Detection of inducible clindamycin resistant strains of Staphylococcus aureus on routine basis is crucial for judicial use of the drug and proper institution of the therapy especially in skin and soft tissue infections.

\section{Introduction}

Staphylococcus aureus forms normal flora of human anterior nares, nasopharynx, perineal area, skin, and various mucosal surfaces. The anterior nares are considered to be primary colonization site and approximately $30 \%$ of healthy people carry the bacteria in their anterior nares (Nilsson and Ripa, 2006).

Skin and soft tissue infections caused by Staphylococcus aureus are frequent worldwide (Layer et al., 2006). Generally, it causes skin infections such as folliculitis, furuncle, carbuncles, impetigo, mastitis, and various wound infections. The Staphylococcus aureus skin and soft tissue infections frequently begin as minor boils or abscesses and may progress to deep infections that spread from skin to cause bacteremia to involve bones, joints, deep organs, scalded skin syndrome in neonates, toxic shock syndrome, and food poisoning (Layer et al., 2006). The severe form of infection can be avoided by giving early treatment like incision and draining the lesion with proper antimicrobial therapy. 
In recent studies carried out worldwide reported that the most of the skin and soft tissue infection are community acquired and methicillin resistant strains of Staphylococcus aureus (MRSA) are one of the major concerns. Evaluation of demographic data as well as history of antimicrobial therapy is most important to overcome the situation. The macrolide-lincosamide-streptogramin B $\left(\mathrm{MLS}_{\mathrm{B}}\right)$ family of antibiotics serves as one such alternative, with clindamycin being the preferred agent due to its excellent pharmacokinetic properties (Fiebelkorn et al., 2003; Saxena et al., 2012). However, widespread use of $\mathrm{MLS}_{\mathrm{B}}$ antibiotics hassled to an increase in number of staphylococcal strains acquiring resistance to $\mathrm{MLS}_{\mathrm{b}}$ (Yilmaz et al., 2007). Clindamycin is used in the treatment of skin and soft-tissue infection, caused by the Staphylococcal species and good oral absorption makes this drug an important option in outpatient therapy. It has wide distribution in inflamed tissue except for the CNS and dosage adjustment will not require even in severe hepatic or renal dysfunctions (Buck, 2008). Clindamycin is also used as an alternative for patients who are allergic to penicillin (Fiebelkorn et al., 2003). However, treatment of an infection using clindamycin or any non-inducer macrolide, caused by a strain carrying inducible erm gene, can lead to clinical failure due to development of resistance (Weisblum, 1995; Kloos, 1999). Three unrelated groups of antimicrobial agents share the same ribosomal binding site in the bacterial cell- macrolide, lincosamide and streptograminB. Therefore, it is possible that to one group of antibiotics (macrolides) might predict resistance to the other groups. Resistance to erythromycin is used as an indicator of possible resistance to clindamycin. Most common mechanism for such resistance is target site modification mediated by erm genes which can be expressed either constitutively (constitutive $\mathrm{MLS}_{\mathrm{B}}$ phenotype) or inducibely (inducible
MLS $_{\mathrm{B}}$ phenotype) (Kumar et al., 2012; Reddy and Suresh, 2017).

The strains with inducible resistance to clindamycin are difficult to detect in the routine laboratory as they appear erythromycin resistant and clindamycin sensitive in-vitro when not placed adjacent to each other. In such case, in-vivo therapy with clindamycin may select constitutive erm mutants leading to clinical therapeutic failure (Deotale et al., 2010). In case of another mechanism of resistance, Staphylococcus aureus can also develop isolated macrolide resistance based on the presence of an efflux pump, encoded by msrA gene leads to resistance to macrolide and type $B$ streptogramins but not to lincosamide. These isolates known as MS phenotype also shown in vitro resistance to erythromycin and sensitive to clindamycin same as in inducible resistance phenotype, but clindamycin therapy can be safely given in infections with this phenotype and there is no risk of clinical failure (Roberts et al., 1999).

Clinical and Laboratory standard Institute (CLSI) recommends the double disk diffusion test (D-test) to detect the presence of phenotypic inducible clindamycin resistance (Wayne, 2007). Reporting Staphylococcus aureus as susceptible to clindamycin without checking for inducible resistance may result in institution of inappropriate clindamycin therapy. On other hand, negative result for inducible clindamycin resistance confirms clindamycin susceptibility and provides a very good therapeutic option (Perez et al., 2007).

\section{Materials and Methods}

After the permission from ethical committee, present study conducted at Department of Microbiology at tertiary care hospital. A total of 176 Staphylococcus aureus were isolated from various clinical specimens. The 
Staphylococcus aureus were isolated by standard techniques like colony morphology, gram staining, catalase test, and coagulase test. All the isolates subjected to antimicrobial susceptibility testing susceptibility testing by Kirby Bauer's disc diffusion method as per CLSI guidelines. The erythromycin resistant strains of Staphylococcus aureus exhibiting skin and soft tissue infection were further subjected to D-test to detect inducible clindamycin resistant strains and routine antimicrobial susceptibility testing as per CLSI guidelines (Wayne, 2007). Clinical history is taken from patient's case paper form to correlate SSTIs.

\section{Antimicrobial susceptibility testing}

\section{Kirby Bauer disc diffusion method}

A well isolated colonies of coagulase positive isolates was taken and suspended in peptone water and incubated at $37^{\circ} \mathrm{C}$ for 4 hours, the bacterial suspension were compared with 0.5 McFarland turbidity standard, comparison was corrected by using addition of peptone water or further incubation. The bacterial suspension was inoculated on Mueller Hinton agar plates, appropriate antibiotic disc was put and incubated at $37^{\circ} \mathrm{C}$ for 24 hours as per CLSI guidelines (Wayne, 2007; Deotale et al., 2010).

\section{D-test}

D-test was performed on erythromycin resistant strains of Staphylococcus aureus to rule out inducible clindamycin resistant strains of staphylococci as per standard guidelines and interpreted as three MLSb phenotypes (Wayne, 2007; Deotale et al., 2010).

\section{Statistical analysis}

Results were analyzed by SPPS 20.0 version software, by using one-sample Chi-square test, one-sample Binomial test and p-value $>0.05$ were considered as statistically significant.

\section{Results and Discussion}

A total 176 Staphylococcus aureus were isolated from various clinical samples, out of which $82(47.15 \%)$ were recovered from skin and soft tissue infections exhibiting erythromycin resistant strains. Staphylococcus aureus is an important pathogen causing Skin and soft tissue infections, toxin mediated infections, and urinary tract infection. The determination of antimicrobial susceptibility of a clinical isolates is often crucial for optimal antimicrobial therapy of infected patients. This is particularly important considering the increase of resistance and emergence of multidrug resistant organisms. There are many options available for treatment of MRSA and MSSA infections, with clindamycin being one of the good alternatives (Fiebelkorn et al., 2003). However, clindamycin resistance can develop in staphylococcal isolates with inducible phenotype, and from such isolates, spontaneous constitutively resistant mutants have arisen both in-vitro and in-vivo during clindamycin therapy (Yilmaz et al., 2007). Reporting Staphylococcus aureus as susceptible to clindamycin without checking for inducible resistance may result in inappropriate clindamycin therapy especially in skin and soft tissue infections.

In the present study, among the erythromycin resistant Staphylococcus aureus $(\mathrm{n}=82)$ exhibiting skin and soft tissue infections, male were 39(47.6) and female were 43(52.4\%), and most of the patients were in the young active age group i.e. - 21-30 years and 41-50 years, so that there was no significant gender difference in the study group. Horieh saderi et al., (2009) reported, out of 244 Staphylococcus aureus, 134 were male and 110 were female. 
Out of 176 erythromycin resistant Staphylococcus aureus, 82 (47.15\%) of Staphylococcus aureus were isolated from skin and soft tissue infections. Out of which $39(43.9 \%)$ were from abscesses, 18 (22.6\%) from diabetic foot ulcer, 13 (15.9\%) from cellulitis, $8 \quad(9.8 \%)$ from surgical site infections and $7(8.5 \%)$ were from boils specimen. Similar observation noted by Horieh saderi et al., (2009), out of 244 Staphylococcus aureus, 106 were isolated from wound/SST infections. B Shrestha et al., (2009) reported skin infection isolates contributed a major part $72.5 \%$ of infection by Staphylococcus aureus followed by lower respiratory tract infection $11.41 \%$ and urinary tract infection 8.7\%. Kumari et al., (2008) reported 64\% Staphylococcus aureus from
pus/SSTIs samples followed by $20 \%$ from blood, $4.8 \%$ device associated and $3.2 \%$ from urine.

Methicillin resistance detected by phenotypic method using cefoxitin (30 $\mathrm{mcg}$ ) disc diffusion method. Recent studies indicated that disc diffusion testing using cefoxitin disc is far superior to most of the currently recommended phenotypic method like oxacillin disc diffusion and oxacillin screen agar testing and is now an accepted method for the detection of MRSA (Skov et al., 2006). Result of cefoxitin disc diffusion test is in accordance with PCR for mecA gene. Thus, the test can be alternative to PCR for detection of MRSA (Anand et al., 2009) (Table 1-5).

Graph.1 Distribution of SSTIs among clinical samples

One-Sample Chi-Square Test

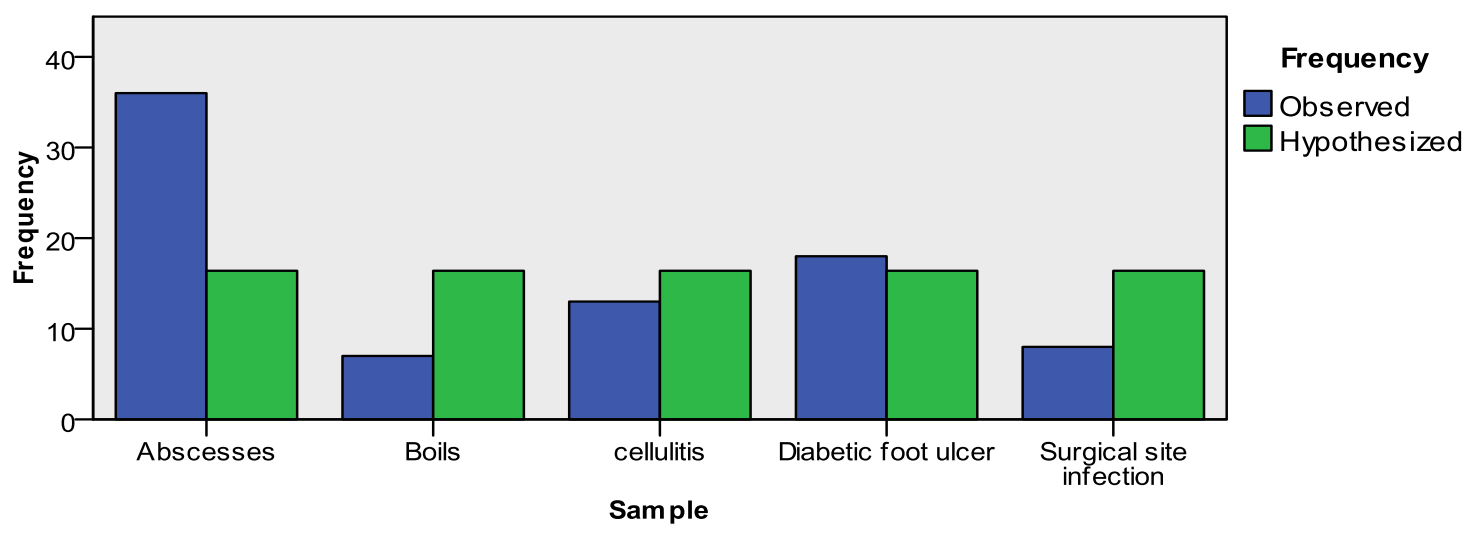

\begin{tabular}{|lr|}
\hline Total N & 82 \\
\hline Test Statistic & 33.976 \\
\hline Degrees of Freedom & 4 \\
\hline Asymptotic Sig. (2-sided test) & .000 \\
\hline
\end{tabular}

1. There are 0 cells $(0 \%)$ with expected values less than 5 . The minimum expected value is 16.400 . 
Graph.2 Age-wise distribution of SSTIs

\section{One-Sample Kolmogorov-Smirnov Test}

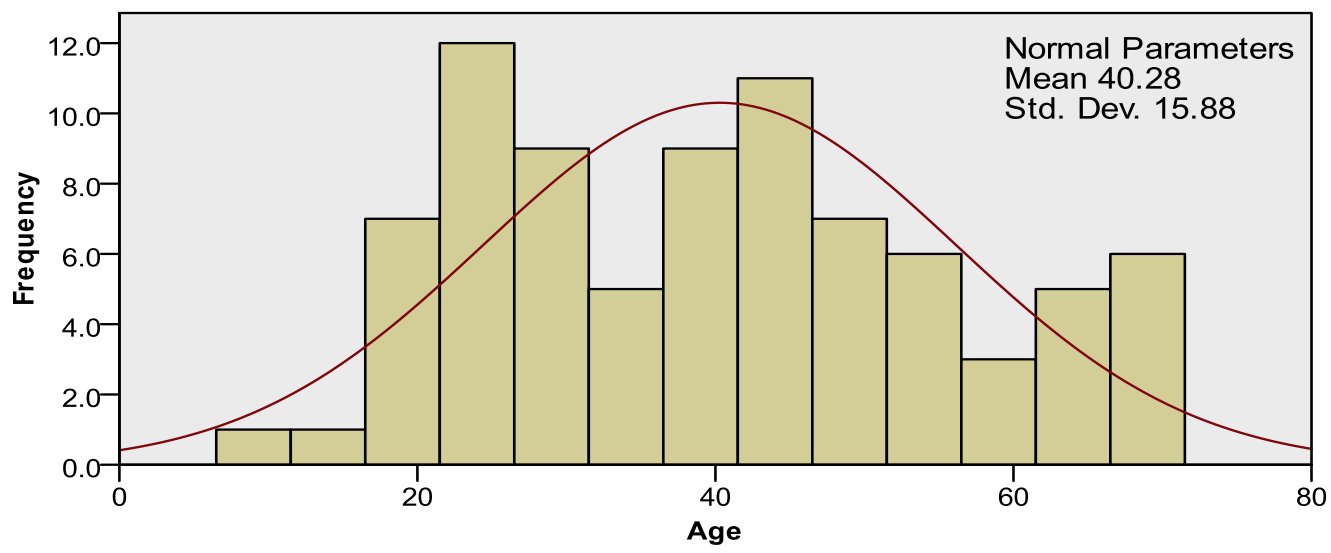

\begin{tabular}{|c|c|c|}
\hline \multicolumn{2}{|l|}{ Total $\mathbf{N}$} & 82 \\
\hline \multirow{3}{*}{ Most Extreme Differences } & Absolute & .107 \\
\hline & Positive & .107 \\
\hline & Negative & -.068 \\
\hline \multicolumn{2}{|l|}{ Test Statistic } & .971 \\
\hline \multicolumn{2}{|c|}{ Asymptotic Sig. (2-sided test) } & .303 \\
\hline
\end{tabular}

Table.1 Distribution of Staphylococcus aureus among clinical samples $(\mathrm{n}=176)$

\begin{tabular}{|l|}
\hline Type of specimen \\
\hline Pus swab from SSTIs \\
\hline Blood \\
\hline Sputum \\
\hline Endotracheal secretion \\
\hline Urine \\
\hline Vaginal swab \\
\hline Pleural fluid \\
\hline Serous fluid \\
\hline Throat swab \\
\hline AC tapping \\
\hline Ear swab \\
\hline TOTAL \\
\hline
\end{tabular}

\begin{tabular}{|l|l|}
\hline Number of samples & Percentage \\
\hline 82 & $47.15 \%$ \\
\hline 28 & $15.90 \%$ \\
\hline 26 & $14.77 \%$ \\
\hline 14 & $7.95 \%$ \\
\hline 14 & $7.95 \%$ \\
\hline 04 & $2.27 \%$ \\
\hline 02 & $1.13 \%$ \\
\hline 01 & $0.56 \%$ \\
\hline 02 & $1.13 \%$ \\
\hline 01 & $0.56 \%$ \\
\hline 176 & $1.13 \%$ \\
\hline
\end{tabular}


Table.2 Demographic data pertaining SSTIs $(n=82)$

\begin{tabular}{|c|c|c|c|c|}
\hline Source & & Frequency & Percent & Cumulative Percent \\
\hline Gender & Female & 43 & 52.4 & 52.4 \\
\hline \multirow{2}{*}{ OPD/IPD } & Male & 39 & 47.6 & 100.0 \\
\hline \multirow{2}{*}{ Distribution of SSTIs } & IPD & 65 & 79.3 & 79.3 \\
\hline & OPD & 17 & 20.7 & 100.0 \\
\cline { 2 - 5 } & Abscesses & 36 & 43.9 & 43.9 \\
\cline { 2 - 5 } & Boils & 7 & 8.5 & 52.4 \\
\cline { 2 - 5 } & Cellulitis & 13 & 15.9 & 68.3 \\
\cline { 2 - 5 } & Diabetic foot ulcer & 18 & 22.0 & 90.2 \\
\hline & Surgical site infection & 8 & 9.8 & 100.0 \\
\hline
\end{tabular}

Table.3 Antimicrobial susceptibility of Staphylococcus aureus exhibiting SSTIs

\begin{tabular}{|c|c|c|c|c|}
\hline \multirow{2}{*}{ Antimicrobial agents } & \multicolumn{2}{|c|}{ Sensitive } & \multicolumn{2}{c|}{ Resistant } \\
\hline & Frequency & Percent & Frequency & Percent \\
\hline Penicillin & 2 & 24 & 80 & 97.6 \\
\hline Cefoxitin(MIC) & 19 & 23.2 & 63 & 76.8 \\
\hline Erythromycin & 00 & 00 & 82 & 100 \\
\hline Clindamycin & 31 & 37.8 & 51 & 62.2 \\
\hline Trimethoprim/Sulfamethoxazole & 22 & 26.8 & 60 & 73.2 \\
\hline Doxycycline & 62 & 75.6 & 20 & 24.4 \\
\hline Levofloxacin & 47 & 57.3 & 35 & 42.7 \\
\hline Amikacin & 60 & 73.2 & 22 & 26.8 \\
\hline Linezolid & 57 & 69.5 & 25 & 30.5 \\
\hline Vancomycin & 82 & 100 & 00 & 00 \\
\hline
\end{tabular}

Table.4 Inducible clindamycin resistant strains of S. aureus exhibiting SSTIs

\begin{tabular}{|l|r|r|r|r|r|}
\hline \multicolumn{7}{|c|}{ Inducible Result } \\
\hline \multicolumn{1}{|c|}{ Type of resistance } & Frequency & Percent & Valid Percent & Cumulative Percent \\
\hline Valid & cMLSb Phenotype & 49 & 59.8 & 59.8 & 59.8 \\
\hline & iMLSb Phenotype & 23 & 28.0 & 28.0 & 87.8 \\
\hline MSb Phenotype & 10 & 12.2 & 12.2 & 100.0 \\
\hline Total & 82 & 100.0 & 100.0 & \\
\hline
\end{tabular}

Table.5 Methicillin resistant strains of S. aureus exhibiting SSTIs

\begin{tabular}{|l|l|r|r|r|r|}
\hline \multicolumn{9}{|c|}{ Methicillin } \\
\hline \multirow{2}{*}{ Valid } & Frequency & Percent & Valid Percent & Cumulative Percent \\
\cline { 2 - 6 } & MSSA & 63 & 76.8 & 76.8 & 76.8 \\
\hline & MSSA & 19 & 23.2 & 23.2 & 100.0 \\
\hline & Total & 82 & 100.0 & 100.0 & \\
\hline
\end{tabular}


In the present study, cefoxitin disc sensitivity revealed that $63(76.8 \%)$ isolates were MRSA and 19 (23.2) were MSSA indicating predominant isolates were MRSA. Horieh Saderi et al., (2009) reported, $54.5 \%$ isolates were MRSA and $45.5 \%$ were MSSA. Nuran Delialioglu et al., (2005) reported $55.65 \%$ isolates were MRSA and $44.34 \%$ were MSSA.

The D-test revealed that the percentage of MLS $_{\mathrm{B}}$ phenotype among Staphylococcus aureus isolated from skin and soft tissue infection specimens, 23 (28\%) isolates tested positive for iMLS $_{\mathrm{B}}$ resistance, $49(59.8 \%)$ were shown to have $\mathrm{cMLS}_{\mathrm{B}}$ and $10(12.2 \%)$ were MS phenotype.

These observation suggest that D-test had not been performed, nearly 23 (28\%) of the erythromycin resistant isolates would have been misidentified as clindamycin sensitive. Reporting these strains as sensitive to clindamycin without performing D-test would have resulted in therapeutic failure.

Similar observation were noted by Deotale et al., (2010) 36 (14.5\%) higher incidence iMLS $_{\mathrm{B}}$ resistance, while Yilmiz et al., (2007) 175 (19.8\%) and Nuran Delialioglu et al., (2005) $18(7.8 \%)$ have indicated lower incidence. Our observation is in concordance with the report by Deotale et al., (2010).

Out of 82 erythromycin resistant Staphylococcus aureus exhibiting SSTIs, 82 (100\%) were sensitive to Vancomycin followed by Doxycyclin 62 (75.6\%), Amikacin 60 (73.2\%), linezolid 57 (69.5\%). Majority of the isolates were resistant to penicillin $80(97.6 \%)$.

In present study, all though we did not studied the prevalence of clindamycin resistance in our area, from the current study; we can conclude that there is high percentage of clindamycin resistance amongst the staphylococcal isolates that shows erythromycin resistance.

Staphylococcal skin and soft tissue infection treatment is important avoid subsequent secondary infection and emergence of MRSA strains are one of the major concern. The best therapeutic alternative, clindamycin is can be the sight of proper institution of the therapy. Hence, detection of inducible clindamycin resistant (true sensitivity) on routine basis is mandatory for judicial use of the drug.

\section{References}

Anand KB, Agrawal P, Kumar S, Kapila K. Comparison of cefoxitin disc diffusion test, oxacillin screen agar, and PCR for $m e c A$ gene for detection of MRSA. Indian journal of medical microbiology. 2009 Jan 1; 27(1):27.

Buck ML. Use of clindamycin in pediatric infections. Pediatric pharm. 2008; 14:2.

Delialioglu N, Aslan G, Ozturk C, Baki V, Sen $\mathrm{S}$, Emekdas G. Inducible clindamycin resistance in staphylococci isolated from clinical samples. Jpn J Infect Dis. 2005 Apr 1; 58(2):104-6.

Deotale V, Mendiratta DK, Raut U, Narang P. Inducible clindamycin resistance in Staphylococcus aureus isolated from clinical samples. Indian journal of medical microbiology. 2010 Apr 1; 28(2):124.

Fiebelkorn KR, Crawford SA, McElmeel ML, Jorgensen JH. Practical disk diffusion method for detection of inducible clindamycin resistance in Staphylococcus aureus and coagulase-negative staphylococci. Journal of clinical microbiology. 2003 Oct 1; 41(10):4740-4.

Kloos WE. Staphylococcus and micrococcus. Manual of clinical microbiology. 1999: 264-82.

Kumar S, Bandyopadhyay M, Bhattacharya K, Bandyopadhyay MK, Banerjee $\mathrm{P}, \mathrm{Pal} \mathrm{N}$, Mondal S, Ghosh T. Inducible clindamycin resistance in staphylococcus isolates from a tertiary care hospital in Eastern India. Annals of Tropical Medicine and Public Health. 2012 Sep 1; 5(5):468.

Kumari N, Mohapatra TM, Singh YI. Prevalence of methicillin-resistant 
Staphylococcus aureus (MRSA) in a tertiary-care hospital in Eastern Nepal. JNMA J Nepal Med Assoc. 2008 Apr 1; 47(170): 53-6.

Layer F, Ghebremedhin B, Moder KA, König W, König B. Comparative study using various methods for identification of Staphylococcus species in clinical specimens. Journal of clinical microbiology. 2006 Aug 1; 44(8):282430.

Nilsson P, and Ripa T. Staphylococcus aureus throat colonization is more frequent than colonization in the anterior nares. Journal of clinical microbiology. 2006 Sep 1; 44(9):3334-9.

Perez LR, Caierão J, Antunes AL, d'Azevedo PA. Use of the D test method to detect inducible clindamycin resistance in coagulase negative staphylococci (CoNS). Brazilian Journal of Infectious Diseases. 2007 Apr; 11(2):186-8.

Reddy PS, and Suresh R. Phenotypic detection of Inducible Clindamycin resistance among the clinical isolates of Staphylococcus aureus by using the lower limit of inter disk space. Journal of Microbiology and Biotechnology Research. 2017 Mar 18; 2(2):258-64.

Roberts MC, Sutcliffe J, Courvalin P, Jensen LB, Rood J, Seppala H. Nomenclature for macrolide and macrolide-lincosamidestreptogramin B resistance determinants. Antimicrobial agents and chemotherapy. 1999 Dec 1; 43(12):2823-30.

Saderi H, Owlia P, Eslami M. Prevalence of Macrolide-Lincosamide-Streptogramin B (MLSB) resistance in S. aureus isolated from patients in Tehran, Iran. Iranian journal of pathology. 2009 Sep 1; 4(4):161-6.

Saxena S, Singh T, Dutta R. Practical disk diffusion method for detection of inducible clindamycin resistance in Staphylococcus aureus at a tertiary care hospital: implications for clinical therapy. The Journal of communicable diseases. 2012 Jun; 44(2):97-102.

Shrestha B, Pokhrel B, Mohapatra T. Study of nosocomial isolates of Staphylococcus aureus with special reference to methicillin resistant $S$. aureus in a tertiary care hospital in Nepal. Nepal Med Coll J. 2009 Jun; 11(2):123-6.

Skov R, Smyth R, Larsen AR, Bolmstrom A, Karlsson A, Mills K, Frimodt-Moller N, Kahlmeter G. Phenotypic detection of methicillin resistance in Staphylococcus aureus by disk diffusion testing and Etest on Mueller-Hinton agar. Journal of clinical microbiology. 2006 Dec 1; 44(12):4395-9.

Wayne PA. Clinical and laboratory standards institute. Performance standards for antimicrobial susceptibility testing. 2007, vol-2(1).

Weisblum B. Insights into erythromycin action from studies of its activity as inducer of resistance. Antimicrobial agents and chemotherapy. 1995 Apr; 39(4):797.

Yilmaz G, Aydin K, Iskender S, Caylan R, Koksal I. Detection and prevalence of inducible clindamycin resistance in staphylococci. Journal of medical microbiology. 2007 Mar 1; 56(3): 342-5.

\section{How to cite this article:}

Harish Ghogare and Sunil Hatkar. 2018. Inducible Clindamycin Resistant Strains of Staphylococcus aureus - Associated Skin and Soft Tissue Infection. Int.J.Curr.Microbiol.App.Sci. 7(10): 1261-1268. doi: https://doi.org/10.20546/ijcmas.2018.710.141 